\title{
E-cigarette use and willingness to smoke: a sample of adolescent non-smokers
}

\author{
Thomas A Wills, ${ }^{1}$ James D Sargent, ${ }^{2}$ Rebecca Knight, ${ }_{1}^{1}$ Ian Pagano, ${ }^{1}$ \\ Frederick X Gibbons ${ }^{3}$
}

${ }^{1}$ Prevention and Control Program, University of Hawaii Cancer Center, Honolulu, Hawaii USA

${ }^{2}$ Cancer Control Research Program, Norris Cotton Cancer Center, Lebanon, New Hampshire, USA

${ }^{3}$ Department of Psychology, University of Connecticut, Storrs, Connecticut, USA

Correspondence to Dr Thomas A Wills, Prevention and Control Program, University of Hawaii Cancer Center, 701 llalo Street, Room 528, Honolulu, HI 96813 , USA; twills@cc.hawaii.edu.

Received 13 March 2015 Accepted 15 July 2015 Published Online First 10 August 2015

\section{ABSTRACT}

Objective There is little evidence on the consequences of using electronic cigarettes (e-cigarette) in adolescence. With a multiethnic sample of non-smokers, we assessed the relation between e-cigarette use and social-cognitive factors that predict smoking of combustible cigarettes.

Methods School-based cross-sectional survey of 2309 high school students (mean age 14.7 years). Participants reported on e-cigarette use and cigarette use; on smoking-related cognitions (smoking expectancies, prototypes of smokers) and peer smoker affiliations; and on willingness to smoke cigarettes. Regression analyses conducted for non-cigarette smokers tested the association between e-cigarette use and willingness to smoke cigarettes, controlling for demographics, parenting, academic and social competence, and personality variables. Structural equation modelling (SEM) analysis tested whether the relation between e-cigarette use and willingness to smoke was mediated through any of the three smoking-related variables.

Results Non-smokers who had used e-cigarettes (18\% of the total sample) showed more willingness to smoke cigarettes compared with those who had never used any tobacco product; the adjusted OR was $2.35(95 \% \mathrm{Cl}$ 1.73 to 3.19 ). SEM showed that the relation between e-cigarette use and willingness to smoke was partly mediated through more positive expectancies about smoking, but there was also a direct path from e-cigarette use to willingness.

Conclusions Among adolescent non-smokers, e-cigarette use is associated with willingness to smoke, a predictor of future cigarette smoking. The results suggest that use of e-cigarettes by adolescents is not without attitudinal risk for cigarette smoking. These findings have implications for formulation of policy about access to e-cigarettes by adolescents.

\section{BACKGROUND}

Use of electronic smoking devices (e-cigarettes) has been increasing rapidly among adolescents. ${ }^{1-3}$ The prevalence of e-cigarette use among adolescents has been increasing 2-3 times or more every year in the USA ${ }^{1}{ }^{2}$ and in other countries including Finland, Korea and Poland. ${ }^{4-6}$ Recent US studies have shown a prevalence of ever-use among high school students ranging from $10 \%$ to $25 \%$ of the adolescent population, ${ }^{7} 8$ with comparable rates observed among adolescents in European and Asian countries. ${ }^{3}$

The increasing prevalence of e-cigarette use has sparked a debate about policy implications. Some have argued that e-cigarettes offer a lower risk approach that may result in cessation of smoking tobacco cigarettes (cigarettes), so restrictions on e-cigarette use should be minimal. ${ }^{9}$ Others have raised a concern that frequent e-cigarette use in public places and aggressive advertising for e-cigarettes in venues where cigarette advertising was previously banned may lead to a renormalisation of cigarette smoking, which would argue for restrictions on e-cigarette use. ${ }^{1}{ }^{10}$ Whether ecigarette use encourages or discourages smoking among adolescents is an important policy question; however, there is little evidence bearing on this. Epidemiological studies show that a substantial proportion of adolescents are dual users, engaging in both e-cigarette use and cigarette smoking, ${ }^{11}{ }^{12}$ but it remains unclear whether e-cigarettes may serve as a cognitive/attitudinal gateway to cigarette smoking. ${ }^{1}{ }^{3}$ Accordingly, the present research tested whether e-cigarette use is associated with adolescents' interest in smoking cigarettes and, if so, how this relationship is mediated.

\section{Consequences of e-cigarette use in adolescence}

Our perspective on the possible consequences of e-cigarette use is that while adolescents may take up e-cigarette use because of curiosity and normative exploration typical of adolescence, ${ }^{13-15}$ they experience the sensory characteristics of inhaling and exhaling vapour, and may begin to form positive expectancies about smoking behaviour. ${ }^{16} 17$ The act of using an e-cigarette can also serve to focus the adolescent's attention on marketing campaigns on television, the internet and social media that portray users as attractive and socially popular. ${ }^{18-21}$ Through attention to marketing, the youth may begin to form positive perceptions of smokers, a cognitive factor that attracts adolescents to smoking. ${ }^{22} 23$ The use of e-cigarettes can encourage beginning to affiliate with peers who also use cigarettes. $^{24-26}$ In addition, using e-cigarettes exposes the adolescent to nicotine, and the physiological effects of nicotine may directly act to institute a negative reinforcement process, ${ }^{27-29}$ thereby forming a route to interest in smoking that is independent of cognitive and social mechanisms. Thus, we measured expectancies about smoking, perceptions of smoking, and affiliation with peer smokers, and examined statistically whether any of these processes were involved in forming positive interest in smoking, as well as testing for a possible direct effect of e-cigarette use on interest in smoking.

At present, two published studies have considered how e-cigarette use is related to interest in smoking. Bunnell et $a l^{30}$ used school-based survey data from representative national samples of 6th12th grade students, with data collected in 2011, 2012 and 2013. Two items on intention to smoke 
were administered with four-point response scales; participants who said 'definitely no' to both questions were coded as not having any intention to smoke, otherwise, they were coded as having intention. Analyses of data for non-smokers indicated that smoking intention was higher among ever e-cigarette users (43.9\%) compared with youth who had never used e-cigarettes (21.5\%). Coleman et al $l^{31}$ used data on persons 18-29 years of age from a nationally representative random-digit dial-a-telephone survey conducted in 2012-2013. Respondents were classified as non-smokers if they said no to questions about whether they had smoked at least 100 cigarettes in their lifetime, and whether they smoked now. Intention to smoke, indexed by procedures similar to Bunnell et al, ${ }^{30}$ was present for $46 \%$ of those who had tried e-cigarettes compared with $14 \%$ for those who had not. Thus, these studies, which had some multivariate controls, both indicated that e-cigarette use was related to more interest in smoking. However, neither of these studies tested how the effect of e-cigarette use was mediated. Moreover, these studies relied on measures of intention to smoke, which can have value for predicting healthpromoting behaviours such as immunisation, ${ }^{32}$ but has less ability to predict risk behaviours such as smoking. ${ }^{22}$ 33-35 Therefore, we examined the effect of e-cigarette use on willingness to smoke among adolescent non-smokers, using a measure that has been validated in several studies for predicting onset of smoking in adolescence. ${ }^{22} 33$ We included a range of psychosocial measures that have not been assessed in previous studies, and used structural equation modelling (SEM) to test how the relation between e-cigarette use and willingness to smoke was mediated. We employed both continuous and dichotomous approaches for analysing willingness to smoke, because some critics of e-cigarette research ${ }^{36}$ have questioned how constructs, such as intention, have been defined.

\section{METHODS}

The data are from a study in which participants were first surveyed in middle school (7th and 8th grades). Items on e-cigarettes were added when participants were in the 9th and 10th grades.

\section{Participants and procedure}

The participants were 2309 students (76\% response rate) in four public and two private high schools (100\% response rate) on Oahu, Hawaii. Data on e-cigarettes were first obtained in this study during 2013 and early 2014. The sample (48\% 9th graders, $43 \% 10$ th graders, $9 \%$ 11th graders) was 53\% female and mean age was 14.7 years $(\mathrm{SD}=0.7)$. Regarding race/ethnicity, $25 \%$ of the participants were of Asian-American background (Chinese, Japanese or Korean), 19\% were Caucasian, $27 \%$ were Filipino-American, $20 \%$ were Native Hawaiian or other Pacific Islander and 9\% were of other race/ethnicity. Regarding family structure, $17 \%$ of participants were living with a single parent, $12 \%$ were in a step-parent family, $60 \%$ were with two biological parents, and $11 \%$ were in an extended family structure. The mean for father's education on a 1-6 scale was 4.2 (SD 1.2), indicating some education beyond high school.

A self-report survey was administered to students in classrooms by trained research staff. Students were instructed that the data were totally confidential, and that they should not write their names on the surveys. The research procedure was reviewed and approved by the institutional review boards of the University of Hawaii and the Hawaii State Department of Education. A consent form was sent to parents, and students with parental consent read an assent form emphasising that participation was voluntary and data were confidential. Research assistants gave general instructions to a class and then distributed a paper survey to assenting students. The assistants remained in the classroom while students worked on the survey to answer any individual questions about particular items.

\section{Measures}

The measures had generally been validated in other populations ${ }^{37-39}$ but scale structure for the psychosocial covariates was verified with factor analysis and internal consistency analysis. A higher score reflects more of the attribute in the variable label.

\section{Demographics}

The student was asked to indicate his/her gender and write in his/her age in years. The family structure item asked "What adults do you live with right now?" Nine response alternatives were provided and the student was told to check one or more as appropriate. For ethnicity, the student was first given 14 fixed ethnic options and was asked "What would you say you are" with the instruction to check one or more as appropriate. A following question told the student that if he/she had checked more than one ethnicity to indicate "If you had to choose only one, what would you say?" with a write-in response. A coding of responses to the latter item was used to index primary perceived ethnicity. Parental education items asked, "What is the highest level of education your father/mother has completed?" with six fixed responses having anchor points Grade School and Post-College.

\section{E-cigarette item}

The item on e-cigarettes was introduced with the stem: "Which of the following is most true for you about smoking electronic cigarettes (E-cigarettes, Volcanos)? (check one)." Responses were on a seven-point scale with anchor points Never Smoked an E-cigarette in My Life to Usually Smoke E-cigarettes Every Day.

\section{Cigarette item}

The item on cigarettes was introduced with the stem: "Which of the following is most true for you about smoking cigarettes? (check one)." Responses were on a seven-point scale with anchor points Never Smoked Cigarettes in My Life to Usually Smoke Cigarettes Every Day.

\section{Willingness items}

The three items in the measure of willingness to smoke ${ }^{23} 33$ were introduced with the stem: "Suppose you were with a group of friends and there were some cigarettes you could have if you wanted. How willing would you be to __:" The items were "Take one puff," "Smoke a whole cigarette" and "Take some cigarettes to try later." Responses were on four-point scales with response points: Not At All Willing (0); A Little Willing (1); Somewhat Willing (2); and Very Willing (3). A composite score for willingness to smoke was the sum of the three items $(\alpha=0.91)$.

\section{Psychosocial covariates}

Variables were included as covariates, because they might be correlated with e-cigarette use and with willingness to smoke ${ }^{12}$ 39-41 are summarised in table 1 . Several measures were derived from parenting theory ${ }^{42}$ and assessed the quality of the parent-adolescent relationship. Two measures were derived from socialcognitive theory ${ }^{43}$ and assessed perceptions of competence and efficacy in academic and social situations. Two measures were 
Table 1 Variables used as covariates and mediators in regression and structural modelling analyses

\begin{tabular}{|c|c|c|}
\hline Variable (items) & $\alpha$ & Sample item \\
\hline \multicolumn{3}{|l|}{ Covariates } \\
\hline Parental support $(5)^{*}$ & 0.94 & $\begin{array}{l}\text { When I feel bad about something, my } \\
\text { parent will listen }\end{array}$ \\
\hline Parental monitoring $(5)^{*}$ & 0.75 & $\begin{array}{l}\text { My parent asks me what I do with my } \\
\text { friends }\end{array}$ \\
\hline Parent-adolescent conflict $(3)^{*}$ & 0.83 & $\begin{array}{l}\text { I have a lot of arguments with my } \\
\text { parent }\end{array}$ \\
\hline Academic competence $(5)^{*}$ & 0.79 & I like school because I do well in class \\
\hline Social competence $(5)^{*}$ & 0.81 & $\begin{array}{l}\text { I find it easy to make friends with } \\
\text { other teens }\end{array}$ \\
\hline Sensation seeking $(5)^{*}$ & 0.75 & $\begin{array}{l}\text { I like to do things that are a little } \\
\text { frightening }\end{array}$ \\
\hline Rebelliousness (4)* & 0.84 & I like to break the rules \\
\hline \multicolumn{3}{|l|}{ Mediators } \\
\hline Smoking expectancies $(5)^{*}$ & 0.94 & $\begin{array}{l}\text { Smoking helps you feel more } \\
\text { self-confident }\end{array}$ \\
\hline Prototypes of smokers (4) $\dagger$ & 0.80 & $\begin{array}{l}\text { The type of person your age who } \\
\text { smokes is popular }\end{array}$ \\
\hline Peer smoker affiliation (1) $\ddagger$ & NA & $\begin{array}{l}\text { Do any of your friends smoke } \\
\text { cigarettes? }\end{array}$ \\
\hline
\end{tabular}

derived from theory on deviance-proneness ${ }^{44}$ and sensation seeking, ${ }^{45}$ and assessed the tendency to rebel against constraints on behaviour and to desire intense, novel stimulation and exciting activities.

\section{Hypothesised mediators}

Three variables, also summarised in table 1 , represented plausible intermediate pathways in the relation between e-cigarette use and to willingness to smoke (see refs 2339 for theoretical basis). A five-item scale on positive expectancies about cigarette smoking assessed whether smoking was perceived as enhancing social confidence and providing relaxation and tension reduction. A fouritem scale on prototypes of smokers assessed the extent to which the typical same-age teen who smoked was perceived as popular, attractive and cool. The item on peer smoking assessed the respondent's affiliation with peers who smoked.

\section{Analysis}

Analyses were performed in SAS and Mplus. ${ }^{46}$ Missing data rates were generally low for individual variables (1-2\%), but parental education was missing for $20 \%$ of the sample and multiple imputation (Proc MI in SAS) was used for regression analyses. Among persons who had never smoked a cigarette, $t$ test compared the mean level of willingness to smoke for persons who had used e-cigarettes, and persons who had never used any tobacco product. We computed adjusted means in SAS including 16 covariates, and examined how mean willingness to smoke varied as a function of level of e-cigarette use. The covariates included in the analyses were gender (dichotomous); ethnicity (four binary variables contrasting Caucasian, Native Hawaiian, Filipino and other ethnicity against Asian Americans as the reference group); family structure (three binary variables, contrasting Single Parent, Blended Family, and Extended Family against Intact family as the reference group); and parental education, dichotomised to high school graduate or less and some college or more. Also included as covariates were continuous scores for parenting (parental support, monitoring and conflict), socialcognitive variables (academic and social competence) and personality variables (rebelliousness and sensation seeking). Logistic and linear regression analyses, including covariates, determined the relation between e-cigarette use and willingness to smoke. SEM was then conducted in Mplus with the EM algorithm used to include missing data in the analysis and school included as a clustering factor. The model was specified with e-cigarette use and the covariates as exogenous. The three hypothesised mediators were specified as endogenous, with residual covariances of their error terms, and willingness to smoke was the criterion. Structural modelling analyses were performed with the criterion variable specified alternately as continuous and as dichotomous. The former model was estimated using maximum likelihood with robust estimates of SEs, the latter model was estimated using the weighted least squares method.

The validity of the willingness measure for predicting smoking onset was evaluated using longitudinal regression analysis based on initial non-smokers in data previously obtained with this sample during the 7th and 8th grades (1-year followups). For a continuous predictor, the adjusted model (including the same covariates) showed the OR for $\mathrm{W} 1$ willingness predicting W2 smoking (never vs ever) was 1.45 (CI 1.13 to 1.86 ). For a dichotomised predictor, the OR for W1 willingness predicting W2 smoking was 2.85 (CI 1.49 to 5.44). Thus the measure of willingness to smoke had validity for predicting smoking onset in this sample.

\section{RESULTS}

Regarding prevalence, $31 \%$ of the participants had ever used ecigarettes and $16 \%$ had ever smoked cigarettes. Cross-classification indicated $18 \%$ of the participants had used e-cigarettes but never smoked cigarettes.

\section{E-cigarette use and willingness to smoke}

The analytic sample was restricted to participants who had used e-cigarettes but had never smoked cigarettes $(n=418)$ and participants who had never used either product (hereafter non-users; $\mathrm{n}=1526$ ). The mean score for willingness to smoke in this sample of non-smokers was 0.28 (SD 0.84), and the distribution had a skewness of 3.87; a log transform reduced skewness to 3.01. The mean score for willingness was 0.21 (SD 0.70) among non-users and was 0.55 (SD 1.19) among e-cigarette users; the $\mathrm{t}$ (unequal variances) was $5.71 \quad(\mathrm{p}<0.0001)$. Unadjusted means and adjusted means for willingness (controlling for the 16 covariates) are presented in table 2 by frequency of e-cigarette use. Willingness to smoke was significantly higher for all levels of e-cigarette use compared with non-users, and pairwise comparisons using Tukey-Kramer adjustment indicated means for different levels of e-cigarette use did not differ significantly from each other. Accordingly, a dichotomous index for ecigarette use (never used vs ever used) was employed in subsequent analyses.

Logistic regression analysis, with status of e-cigarette use (never vs ever) as the predictor and dichotomised willingness to smoke (zero willingness vs any willingness) as the criterion, indicated $26 \%$ of e-cigarette users showed willingness to smoke compared with $11 \%$ of non-users. This difference was significant, with adjusted $\mathrm{OR}=2.35,95 \% \mathrm{CI}=1.73$ to 3.19 . Multiple regression with a continuous score for willingness (log transformed) as the criterion indicated that the standardised regression coefficient for e-cigarette use was $\beta=0.18 \quad(t=6.54$, $\mathrm{p}<0.0001)$ in the unadjusted analysis, and was $\beta=0.13(\mathrm{t}=4.39$, 
Table 2 Mean (SE in parentheses) for willingness to smoke in relation to level of e-cigarette use among adolescent non-smokers

\begin{tabular}{|c|c|c|c|c|c|c|}
\hline & \multicolumn{5}{|c|}{ Frequency of use (number of cases) } & \\
\hline & Never & 1-2 times & 3-4 times & Yearly/Monthly & Weekly/Daily & \\
\hline Analysis & [1526] & [160] & [169] & [50] & [39] & $\mathrm{F}$ \\
\hline \multirow[t]{2}{*}{ Unadjusted } & 0.16 & $0.39 a$ & $0.37 a$ & $0.57 a$ & $0.56 a$ & $15.50^{* * * *}$ \\
\hline & $(0.02)$ & $(0.05)$ & $(0.05)$ & $(0.09)$ & $(0.10)$ & \\
\hline \multirow[t]{2}{*}{ Adjusted } & 0.17 & $0.33 a$ & $0.33 a$ & $0.47 a$ & $0.47 a$ & $7.32^{* * * *}$ \\
\hline & $(0.02)$ & $(0.05)$ & $(0.05)$ & $(0.09)$ & $(0.10)$ & \\
\hline
\end{tabular}

Adjusted means based on 16 covariates including demographics, parenting, competence and personality. Higher levels of e-cigarette use are collapsed in cells for yearly/monthly use and weekly/daily use so as to increase power for pairwise comparisons. Cells with a common subscript do not differ significantly ( $p>0.05$ ) in pairwise comparisons with Tukey-Kramer adjustment.

$* * *$ indicates $p<0.0001$.

$\mathrm{p}<0.0001$ ) in the adjusted analysis (including 16 covariates). Thus, the relation between e-cigarette use and willingness to smoke was significant for both dichotomous and continuous indices of willingness, and was independent of a range of demographic and psychosocial covariates.

\section{Structural equation modelling of mediation}

SEM analysis was performed in Mplus, with the model specified as described previously. The zero-order correlations among ecigarette use, the covariates, the hypothesised mediators and willingness to smoke are presented in table 3 . Almost all the psychosocial covariates were significantly related to e-cigarette use. The hypothesised mediators all had significant zero-order correlations with willingness to smoke; the highest correlations were for expectancies and prototypes, and the lowest was for peer smoker affiliations.

Structural modelling analyses were performed with willingness to smoke as a continuous variable (log transformed) and as a dichotomous variable (zero willingness vs any willingness). Initial models were estimated with all paths from the exogenous variables to the mediators and with paths from each of the hypothesised mediators to willingness. Non-significant exogenous paths were then trimmed from the model. Additional paths were included on the basis of modification indices $>30$; these were direct effects to willingness from: parent-adolescent conflict, e-cigarette use and parental monitoring. The final model with a continuous criterion had $\chi^{2}(51 \mathrm{df}, \mathrm{N}=1944)$ of 87.87 and Comparative Fit Index $(\mathrm{CFI})=0.95$, parameters indicating reasonable fit of the model to the data. The final model with a dichotomous criterion had $\chi^{2}$ (computed $40 \mathrm{df}, \mathrm{N}=1944$ ) of 69.42 and $\mathrm{CFI}=0.99$, these parameters indicating excellent fit. Structural coefficients were very similar in the two models, however, the analysis with a dichotomous criterion had better fit and the model accounted for more of the variance in the criterion. This model is presented in figure 1 .

Overall, the variables in the model accounted for $25 \%$ of the variance in willingness to smoke cigarettes. E-cigarette use had positive paths to peer smoker affiliations and smoking expectancies, and a direct effect to willingness, but the path from ecigarette use to prototypes of smokers was non-significant. Paths from expectancies and prototypes to willingness to smoke were both significant but the path from peer affiliations to willingness was not. (This path was significant in the initial model but became non-significant when the direct effect from e-cigarette use was included.) There was a significant indirect effect from ecigarette use through expectancies to willingness, Critical Ratio $(C R)=2.12(p<0.05)$, and a significant direct effect from ecigarette use to willingness, $C R=4.84(p<0.0001)$. The direct effect from e-cigarette use to willingness to smoke was the most prominent feature in the model, representing $91 \%$ of the total effect, whereas the indirect effect through expectancies represented $9 \%$ of the total effect.

Other results in the structural model were paths from parentadolescent conflict to peer smoker affiliations and favourable prototypes of smokers, plus a direct effect to more willingness to smoke. Sensation seeking and rebelliousness had positive paths to peer smoker affiliations, expectancies about smoking, and prototypes of teen smokers. Regarding protective factors, participants with higher academic involvement had fewer peer smoker affiliations and more unfavourable prototypes of teen smokers, and parental monitoring had an inverse direct effect on willingness to smoke. Single-parent family was related to more peer smoker affiliations $(p<0.05)$, and male gender related to less favourable prototypes of smokers $(p<0.01)$. Social competence had a positive path to peer smoker affiliations, a suppression effect because the zero-order correlation with peer affiliations was non-significant (table 3), but there was a significant effect in the multivariate model. Most of these effects have been observed before, ${ }^{33}$ 37-39 41 including the suppression effect for social competence. ${ }^{42}$ These findings together exemplify the multifactorial nature of adolescent substance use, which has predictive effects from parent, peer and personality variables. 25 39-40 4748

\section{DISCUSSION}

This research was conducted to obtain data bearing on the question of whether e-cigarette use among adolescents is related to their interest in smoking cigarettes. The data were from a diverse sample of high school students, and analyses were conducted with control for a range of demographic and psychosocial covariates. Results indicated that e-cigarette use was positively related to willingness to smoke cigarettes. Also, the relation between e-cigarettes and willingness to smoke was partly mediated through expectancies about smoking, though a direct effect from e-cigarette use to willingness was the most salient aspect of the model. The findings were robust across dichotomous and continuous definitions of willingness to smoke, and the willingness measure was shown to be prospectively related to onset of smoking behaviour in this sample.

The direct path from e-cigarette use to willingness to smoke, independent of other variables in the model, had an effect size comparable to paths observed for established predictors of adolescent smoking, such as parental monitoring and parent-adolescent conflict. ${ }^{41} 42$ Clearly it is an important part of the process. A behavioural interpretation suggests that because many e-cigarettes are designed to mimic cigarette smoking, simply 
Table 3 Correlations of study variables among adolescent non-smokers

\begin{tabular}{|c|c|c|c|c|c|c|c|c|c|c|c|c|c|c|c|c|c|c|c|c|c|}
\hline Variable & 1. & 2. & 3. & 4. & 5. & 6. & 7. & 8. & 9. & 10. & 11. & 12. & 13. & 14. & 15. & 16. & 17. & 18. & 19. & 20. & 21. \\
\hline 1. E-cigarette use & - & & & & & & & & & & & & & & & & & & & & \\
\hline 2. Gender (male) & 0.05 & - & & & & & & & & & & & & & & & & & & & \\
\hline 3. Native Hawaiian & 0.12 & -0.04 & - & & & & & & & & & & & & & & & & & & \\
\hline 4. Filipino & 0.07 & 0.00 & -0.30 & - & & & & & & & & & & & & & & & & & \\
\hline 5. Caucasian & -0.03 & 0.06 & -0.22 & -0.30 & - & & & & & & & & & & & & & & & & \\
\hline 6. Other ethnicity & 0.03 & 0.00 & -0.15 & -0.20 & -0.15 & - & & & & & & & & & & & & & & & \\
\hline 7. Single parent & 0.08 & 0.00 & 0.02 & -0.02 & 0.01 & 0.10 & - & & & & & & & & & & & & & & \\
\hline 8. Blended family & 0.02 & -0.03 & 0.02 & -0.08 & 0.04 & 0.04 & -0.14 & - & & & & & & & & & & & & & \\
\hline 9. Extended family & 0.07 & 0.01 & 0.04 & 0.18 & -0.12 & -0.06 & -0.15 & -0.12 & - & & & & & & & & & & & & \\
\hline 10. Parent education & -0.10 & -0.01 & -0.20 & -0.08 & 0.06 & 0.01 & -0.09 & -0.05 & -0.08 & - & & & & & & & & & & & \\
\hline 11. Parental support & -0.13 & 0.06 & 0.01 & -0.14 & 0.05 & 0.02 & -0.03 & -0.05 & -0.05 & 0.03 & - & & & & & & & & & & \\
\hline 12. Parental monitoring & -0.11 & -0.02 & 0.06 & -0.03 & -0.04 & 0.03 & -0.03 & -0.04 & -0.03 & -0.03 & 0.41 & - & & & & & & & & & \\
\hline 13. Parent-adolescent conflict & 0.13 & -0.07 & 0.01 & 0.03 & -0.02 & 0.02 & 0.03 & 0.06 & 0.01 & -0.02 & -0.55 & -0.09 & - & & & & & & & & \\
\hline 14. Academic involve & -0.18 & -0.03 & -0.08 & -0.01 & -0.03 & -0.01 & -0.04 & -0.02 & -0.06 & 0.10 & 0.35 & 0.32 & -0.23 & - & & & & & & & \\
\hline 15. Social competence & 0.05 & 0.14 & 0.06 & -0.10 & 0.06 & 0.01 & -0.02 & -0.03 & -0.03 & 0.05 & 0.29 & 0.17 & -0.16 & 0.44 & - & & & & & & \\
\hline 16. Sensation seeking & 0.21 & 0.10 & 0.11 & 0.06 & 0.03 & 0.02 & 0.04 & 0.07 & 0.09 & -0.05 & -0.15 & -0.09 & 0.22 & -0.12 & 0.10 & - & & & & & \\
\hline 17. Rebelliousness & 0.27 & 0.16 & 0.11 & -0.04 & 0.06 & 0.02 & 0.03 & 0.05 & 0.04 & -0.03 & -0.25 & -0.20 & 0.35 & -0.29 & 0.06 & 0.49 & - & & & & \\
\hline 18. Peer smoking & 0.20 & 0.06 & 0.07 & -0.04 & 0.02 & 0.01 & 0.07 & 0.04 & 0.04 & -0.05 & -0.12 & -0.09 & 0.18 & -0.16 & 0.09 & 0.25 & 0.30 & - & & & \\
\hline 19. Smoking expectancy & 0.11 & 0.02 & -0.01 & 0.00 & 0.01 & -0.03 & 0.01 & -0.04 & 0.04 & 0.01 & -0.09 & -0.10 & 0.12 & -0.10 & -0.03 & 0.14 & 0.20 & 0.17 & - & & \\
\hline 20. Smoker prototype & 0.04 & -0.05 & -0.01 & 0.02 & -0.02 & 0.04 & 0.01 & 0.00 & 0.01 & -0.01 & -0.07 & -0.03 & 0.13 & -0.11 & -0.05 & 0.11 & 0.13 & 0.24 & 0.20 & - & \\
\hline 21. Willingness to smoke & 0.18 & -0.04 & -0.01 & -0.01 & 0.02 & -0.01 & 0.00 & 0.00 & 0.01 & 0.04 & -0.14 & -0.13 & 0.18 & -0.14 & -0.06 & 0.16 & 0.23 & 0.15 & 0.25 & 0.17 & - \\
\hline
\end{tabular}

$\mathrm{N}$ for correlations=1944. Approximate significance levels are: $|r|>0.06, p<0.01 ;|r|>0.08, p<0.001 ; r>|0.10|, p<0.0001$. 


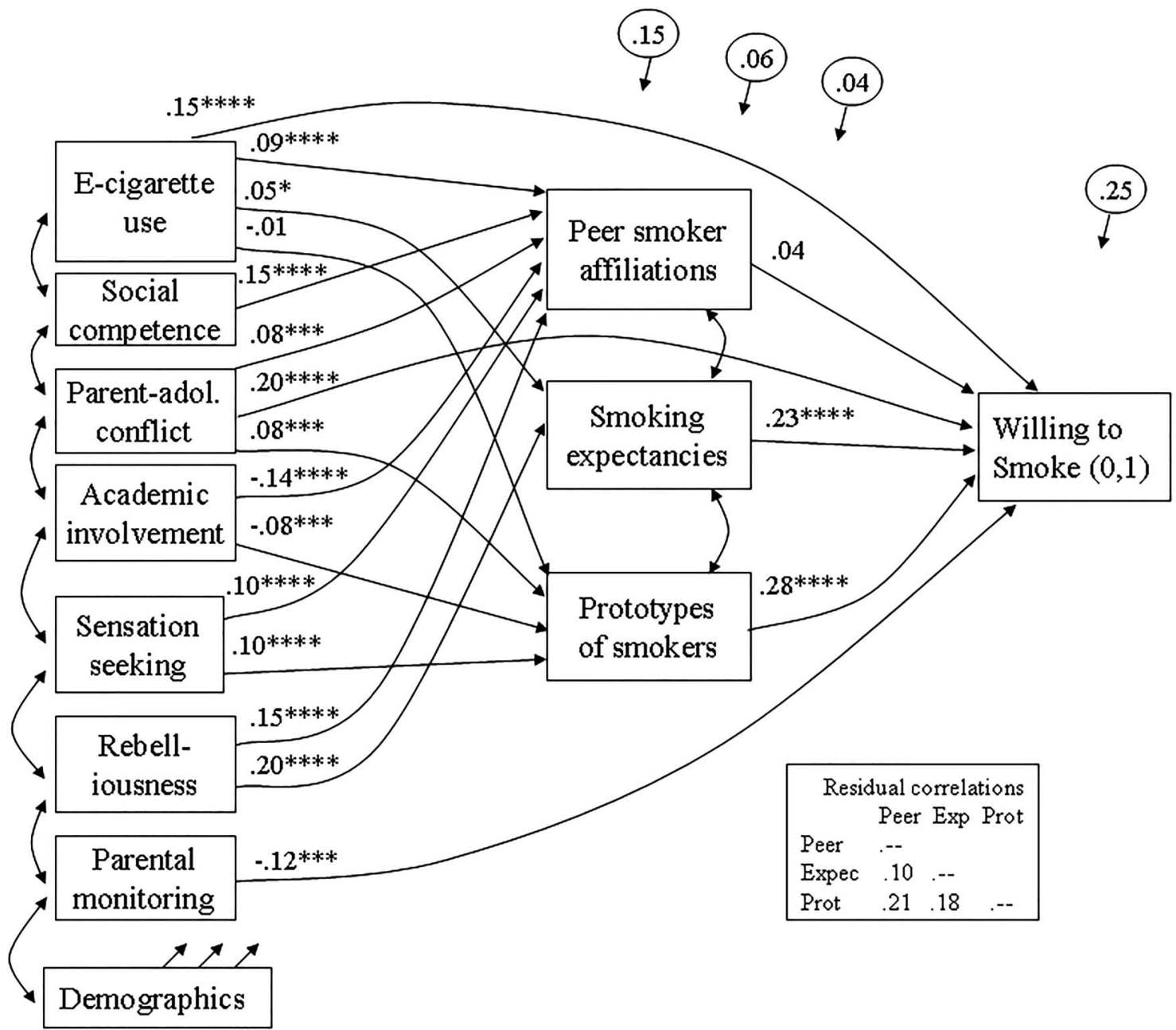

Figure 1 Structural model for relation between e-cigarette use and willingness to smoke cigarettes. Straight single-headed arrows are regression (path) effects, curved double-headed arrows indicate covariances. Values are standardised coefficients. ** Indicates coefficient significant at $p<0.01$; ${ }^{* * *} p<0.001 ;{ }^{* * *} p<0.0001$. Values in circles at top of figure are squared multiple correlations, the variance accounted for in a given construct by all constructs to the left of it in the model. Residual correlations among endogenous variables are in a box in the figure. Demographics (gender, ethnicity, family structure and parental education) were included in the model but are excluded from the figure for graphical simplicity; for correlations among exogenous variables see table 3. Parental support was included in the model but had no significant unique effects.

learning the physical process of inhaling and exhaling vapour and experiencing pleasurable effects from flavours could be an aspect of e-cigarette use that influences attitudes toward smoking. A physiological interpretation suggests that among regular users, frequent exposure to nicotine in adolescence, when the brain is particularly sensitive to this substance, could promote the transition to cigarettes because they are more efficient at delivering nicotine. ${ }^{128}{ }^{49}$ Further research is needed to understand the role of sensory and physiological factors for affecting interest in smoking, particularly because the e-cigarette industry is currently making efforts to enhance the nicotine dose acquired through e-cigarettes. ${ }^{50}$

The finding that e-cigarette use by adolescent non-smokers was related to attitudes that predict their cigarette smoking in the future has significant implications for the policy debate about the risk/benefit ratio of e-cigarettes, the key question being whether use of e-cigarettes increases risk for transition to combustible products. ${ }^{1}{ }^{1} 105152$ The present findings converge with results from other studies with various designs indicating that e-cigarette use is associated with interest in smoking. ${ }^{30} 31$ Moreover, the fact that users of e-cigarettes only are intermediate in risk status between non-users and dual users ${ }^{12}$ is consistent with the hypothesis that e-cigarettes may operate to recruit lower risk adolescents to smoking. This accumulating body of evidence from different types of studies suggests a possible behavioural risk consequence of e-cigarette use in adolescence, which should be weighed together with any benefit that might occur for adult smokers who use e-cigarettes. ${ }^{1}{ }^{9} 52$

Some aspects of the present study could be noted as possible limitations and should be considered for interpretation of the results. The study was conducted in one geographic area and although findings with Hawaii adolescents are consistent with studies conducted elsewhere, ${ }^{12}{ }^{37}$ studying e-cigarette use in different settings is likely to provide a better understanding of etiological factors. The design was cross-sectional, so, temporal relationships are not decisively established, and further research may be designed to study longitudinal relations of variables and possible reciprocal relationships. Finally, e-cigarettes come in many varieties, and the product lines and flavours may vary considerably across manufacturers. ${ }^{1}{ }^{2}{ }^{8}$ Detailed studies of ecigarette products are needed to keep up with a field that is likely to be continually evolving.

In summary, our study contrasted a formulation suggesting that e-cigarette use carries little risk for adolescents with a 
model positing effects on cognitive-attitudinal factors that predispose adolescents to smoke cigarettes. On the balance, our results are most consistent with the latter model. These empirical findings provide evidence supporting policy recommendations to make e-cigarettes less accessible to adolescents through age restrictions, taxation and clean-air policies that apply the same regulations to e-cigarettes as are now applicable for tobacco.

\section{What this paper adds}

- E-cigarette use is increasingly prevalent among adolescents in many countries, but there is little evidence on the consequences of e-cigarette use in adolescence, for example, whether use affects risk for transition to the combustible product.

- This study found that among adolescent non-smokers, those who had used e-cigarettes showed more positive expectancies about smoking cigarettes and more willingness to smoke them, an attitude that prospectively predicted smoking in this sample. These results have implications for formulation of policy about access to e-cigarettes by adolescents.

Acknowledgements The authors thank the Superintendent of the Hawail Department of Education and the Principals of the schools for their support, the participating parents and students for their cooperation, and Zaldymar Cortez, Russel Fisher, Melissa Jasper, and Mercedes Harwood-Tappé for their able assistance with data collection.

Contributors TAW, FXG and JDS designed the parent study. TAW and RK were responsible for the conduct of the research. RK was responsible for the design of the e-cigarette study and preparation of the data for analysis. TAW, IP and JDS conducted the statistical analyses. TAW wrote the first draft of the paper. All authors provided input on manuscript drafts and made substantial contributions to the reporting and interpretation of the results.

Funding This research was supported by grants R01 CA153154 and P30 CA071789-14S4 from the National Cancer Institute.

Competing interests None declared.

Ethics approval The study was approved by the Institutional Review Boards for University of Hawaii and Hawaii Department of Education.

Provenance and peer review Not commissioned; externally peer reviewed.

Data sharing statement Data will be made available to qualified researchers when the study is completed. Data will be posted on a website and requests to use the data will be reviewed by a committee of three co-investigators.

\section{REFERENCES}

1 Grana R, Benowitz N, Glantz SA. E-cigarettes: a scientific review. Circulation 2014;129:1972-86.

2 Pepper JK, Brewer NT. Electronic nicotine delivery system (electronic cigarette) awareness, use, reactions and beliefs: a systematic review. Tob Control 2014;23:375-84.

3 Dutra LM, Glantz SA. High international electronic cigarette use among never smoker adolescents. J Adolesc Health 2014;55:595-7.

4 Goniewicz ML, Gawron M, Nadolska J, et al. Rise in electronic cigarette use among adolescents in Poland. J Adolesc Health 2014;55:713-15.

5 Kinnunen JM, Ollila H, El-Amin SE-T, et al. Awareness and determinants of electronic cigarette use among Finnish adolescents in 2013: a population-based study. Tob Control 2015;24:e264-70.

6 Lee S, Grana R, Glantz S. Electronic cigarette use among Korean adolescents. J Adolesc Health 2014:54:684-90.

7 Arrazola RA, Neff LJ, Kennedy SM, et al. Tobacco use among middle and high school students: United States-2013. MMWR Morb Mortal Wkly Rep 2014:63:1021-6.

8 Krishnan-Sarin S, Morean ME, Camenga DR, et al. E-cigarette use among high school and middle school students in Connecticut. Nicotine Tob Res 2014;17:810-18.
9 Cobb NK, Abrams DB. The FDA, e-cigarettes, and the demise of combusted tobacco. N Engl J Med 2014;371:1469-71.

10 Fairchild AL, Bayer R, Colgrove J. The renormalization of smoking? E-cigarettes and the tobacco endgame. N Engl I Med 2014:370:293-5.

11 Dutra LM, Glantz SA. Electronic cigarettes and conventional cigarette use among US adolescents. JAMA Pediatr 2014;168:610-17.

12 Wills TA, Knight $R$, Williams $R$, et al. Risk factors for exclusive e-cigarette use and dual e-cigarette and tobacco use in adolescents. Pediatrics 2015;135: e43-51.

13 Steinberg L. Risk taking in adolescence: new perspectives from brain and behavioral science. Curr Dir Psychol Sci 2007;16:55-9.

14 Kong G, Morean ME, Cavallo DA, et al. Reasons for electronic cigarette experimentation and discontinuation among adolescents and young adults. Nicotine Tob Res 2015;17:847-54..

15 Pepper JK, Ribisl KM, Emery SL, et al. Reasons for starting and stopping electronic cigarette use. Int J Envir Res Pub Health 2014;11:10345-61.

16 Patel $A B$, Fromme K. Outcome expectancies and substance use. In: Scheier LM, ed. Handbook of drug use etiology. Washington DC: American Psychological Association, 2010:147-64.

17 Wetter DW, Smith SS, Kenford SL, et al. Smoking outcome expectancies: factor structure, predictive validity, and discriminant validity. J Abn Psychol 1994;103:801-11.

18 Richardson A, Ganz 0, Vallone D. Surveillance and characterization of online tobacco and e-cigarette advertising. Tob Control 2015;24:341-7.

19 Grana RA, Ling PM. "Smoking revolution": a content analysis of electronic cigarette retail websites. Am J Prev Med 2014;46:395-403.

20 Richardson A, Ganz O, Vallone D. The cigar ambassador: how Snoop Dogg uses Instagram to promote tobacco use. Tob Control 2014;23:79-60.

21 Duke JC, Lee YO, Kim AE, et al. Exposure to electronic cigarette television advertisements among youth and young adults. Pediatrics 2014;134:e29-36.

22 Gibbons FX, Gerrard M, Lane DJ. A social reaction model of adolescent health risk. In: Suls JM, Wallston KA, eds. Social psychological foundations of health and illness. Oxford, UK: Blackwell, 2003:107-36.

23 Gibbons FX, Houlihan AE, Gerrard M. A dual-focus perspective on prevention of adolescent risk behavior. Br J Health Psychol 2009;14:231-48.

24 Dishion TJ, Piehler TF, Myers, MW. Dynamics and ecology of adolescent peer influence. In: Prinstein M, Dodge K, eds. Understanding peer influence in children and adolescents. New York: Guilford, 2008:72-93.

25 Hoffman BR, Sussman S, Unger J, et al. Peer influences on adolescent cigarette smoking: a theoretical review. Sub Use Misuse 2006;41:103-55.

26 Sussman S, Pokhrel P, Ashmore RD, et al. Adolescent per group identification and characteristics: a review. Addict Behav 2007;32:1602-27.

27 Baker TB, Piper ME, McCarthy DE, et al. Addiction motivation reformulated: an affective processing model of negative reinforcement. Psychol Rev 2004;111:33-51.

28 Dawkins L, Corcoran O. Acute electronic cigarette use: nicotine delivery and subjective effects in regular users. Psychopharmacology 2014;231:401-7.

29 McCarthy DE, Curtin JJ, Piper ME, et al. Negative reinforcement: possible clinical implications of an integrative model. In: Kassel JD, ed. Substance abuse and emotion. Washington DC: American Psychological Association, 2010:15-42.

30 Bunnell RE, Agaku IT, Arrazola RA, et al. Intentions to smoke cigarettes among never-smoking US middle and high school electronic cigarettes users, National Youth Tobacco Survey, 2011-2013. Nicotine Tob Res 2015;17:228-35.

31 Coleman BN, Apelberg BJ, Ambrose BK, et al. Association between electronic cigarette use and openness to cigarette smoking, US young adults. Nicotine Tob Res 2015:17:212-18.

32 McEachan RRC, Conner M, Taylor NJ, et al. Prospective prediction of health-related behaviors with the theory of planned behavior: a meta-analysis. Health Psychol Rev 2011:5:97-144.

33 Gerrard M, Gibbons FX, Houlihan AE, et al. A dual-process approach to health risk decision making: The prototype-willingness model. Devel Rev 2008;28:29-61.

34 Hukkelberg SS, Dykstra JL. Using the prototype/willingness model to predict smoking behavior among Norwegian adolescents. Addict Behav 2009:34:270-6.

35 Rivis A, Sheeran P, Armitage CJ. Explaining adolescents' cigarette smoking-a comparison of four modes of action control and test of the role of self-regulatory mode. Psychol Health 2010;25:893-909.

36 Phillips CV. CDC refines their lies about kids and e-cigarettes. 2014. http:/l antithrlies.com/2014/08/26/cdc-refines-their-lies-about-kids-and-e-cigarettes.

37 Wills $T A$, Bantum EO, Pokhrel P, et al. A dual-process model of early substance use: tests in two diverse populations of adolescents. Health Psychol 2013;32:533-42.

38 Wills TA, Pokhrel P, Morehouse E, et al. Behavioral and emotional regulation and adolescent substance use problems: a test of moderation effects in a dual-process model. Psychol Addict Behav 2011;25:279-92.

39 Gibbons FX, Stock ML, Gerrard M, et al. The prototype-willingness model. In: Conner M, Norman P, eds. Predicting and changing health behaviour: research and practice with social cognition models. 3rd edn. Berkshire, UK: Open University Press, 2015:189-224. 
40 Scheier LM, ed. Handbook of drug use etiology. Washington DC: American Psychological Association, 2010.

41 Wills TA, Sargent JD, Stoolmiller M, et al. Movie smoking exposure and smoking onset: a longitudinal study of mediation processes in a representative sample of US adolescents. Psychol Addict Behav 2008;22:269-77.

42 Wills TA, Forbes M, Gibbons FX. Parental and peer support: an analysis of their relations to adolescent substance use. In: Scheier LM, Hansen WB, eds. Parenting and teen drug use. New York: Oxford, 2014:148-65.

43 Bandura A. Social foundations of thought and action: a social cognitive theory. Englewood Cliffs, NJ: Prentice Hall, 1986.

44 Costa FM, Jessor R, Turbin MS. College student involvement in cigarette smoking: the role of psychosocial and behavioral protection and risk. Nic Tob Res 2007:9:213-24.

45 Zuckerman M. Sensation seeking and risky behavior. Washington DC: American Psychological Association, 2007.

46 Muthén L, Muthén B. Mplus user's guide. Los Angeles, CA: Author, 2010.
47 Pentz MA, Shin HS, Riggs N, et al. Parent, peer, and executive function relationships to early adolescent e-cigarette use. Addict Behav 2015;42:73-8.

48 Wills TA, Sussman S, McGurk M. Identity development and substance use in adolescence. In: Brown S, Zucker RA, eds. Oxford handbook of adolescent substance abuse. New York: Oxford University Press, 2015. In press.

49 Farsalinos KE, Spyrou A, Tsimopoulou K, et al. Nicotine absorption from electronic cigarette use: comparison between first and new-generation devices. Sci Rep 2014;4133:1-7.

50 Meier B. Race to deliver nicotine's punch, but with less risk. New York Times, 24 December 2014, page A1.

51 Fiore MC, Schroeder SA, Baker TB. Strategies for targeting combustible tobacco use. N Engl J Med 2014;370:297-9.

52 Hajek P, Etter JF, Benowitz N, et al. Electronic cigarettes: review of use, content, safety, effects on smokers, and potential for harm and benefit. Addiction 2014;109:1801-10. 